\title{
Utilização de recursos vegetais em áreas de quintais em uma comunidade rural localizada no entorno do Parque Nacional de Sete Cidades, Piauí, Nordeste do Brasil
}

\section{Emanuela Gonçalves dos Santos ${ }^{1}$, Suellen da Silva Santos ${ }^{1}$, Vandermond do Nascimento Gonçalves ${ }^{1}$, Bartolomeu Israel de Souza $^{2}$ e Reinaldo Farias Paiva de Lucena ${ }^{1}$,*}

${ }^{1}$ Laboratório de Etnobiologia e Ciências Ambientais. Departamento de Sistemática e Ecologia. Programa de Pós-Graduação em Desenvolvimento e Meio Ambiente (PRODEMA). Centro de Ciências Exatas e da Natureza. Universidade Federal da Paraíba. João Pessoa-PB, Brasil (CEP 58051-900). *E-mail: rfplnal@gmail.com.

${ }^{2}$ Departamento de Geociências e Programa de Pós-Graduação em Desenvolvimento e Meio Ambiente (PRODEMA). Centro de Ciências Exatas e da Natureza. Universidade Federal da Paraíba. João Pessoa-PB, Brasil (CEP 58051-900).

Resumo. Os sistemas agroflorestais consistem em práticas tradicionais de uso da terra apresentando como principais finalidades o cultivo de espécies vegetais para fins de subsistência e aumento na renda familiar. 0 presente estudo foi conduzido na Comunidade Cachoeira no Município de Brasileira, Estado do Piauí, buscando identificar o conhecimento e uso sobre espécies botânicas cultivadas em quintais rurais e caracterizar a dinâmica que envolve a prática nesses espaços. Os informantes da pesquisa foram chefes domiciliares que atuam na manutenção desses espaços (17 mantenedores). Utilizaram-se formulários semiestruturados com perguntas sobre questões socioeconômicas e específicas relacionadas aos quintais, tais como espécies encontradas na área, finalidades de uso, modo de manutenção e tamanho do quintal. Foi calculado o valor de uso (VU) das espécies tentando elencar a importância local das plantas na visão desses atores sociais. Foram registradas 62 plantas, contudo foi possível a identificação científica de 51 espécies, 46 gêneros e 29 famílias. A pesquisa apontou informações sobre as relações socioculturais entre as pessoas e as plantas presentes na área estudada, que envolvem o conhecimento e uso de espécies botânicas; econômicas, remetendo-se a venda de recursos excedentes, tanto de plantas quanto de animais cultivados nesses espaços; e ecológica, tratando-se do cultivo e manejo de espécies nativas e/ou exóticas. Os dados apresentados poderão ser utilizados em estratégias conservacionistas e sustentabilidade dos recursos vegetais.
Recebido:

$04 / 05 / 2019$

Aceito:

$25 / 07 / 2019$

Disponível on line: $27 / 07 / 2019$

Publicado:

31/08/2019

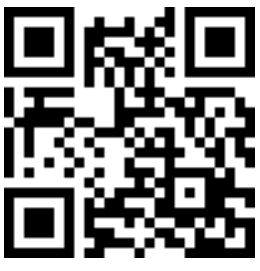

Acesso aberto

D 0000-0003-4116-7731 Emanuela Gonçalves dos Santos

(1) 0000-0001-7280-7856 Suellen da Silva Santos 
Palavras-chave: Agrossistemas; Etnobotânica; Unidade de conservação.

\begin{abstract}
Plant resource utilization in backyard areas in a rural community located around the Sete Cidades National Park, Piauí, Northeast Brazil. Agroforestry systems consist of traditional practices of land use with the main purposes of cultivating plant species for subsistence purposes and increasing household income. This study was conducted in the Community of Cachoeira in the Municipality of Brasileira, Piauí State, Brazil, and aimed to identify the knowledge and use of plant species grown in rural homegardens and characterize the dynamics of this practice in these spaces. Semi-structured interviews were conducted with breadwinners who work in the maintenance of these yards (17 maintainers). The semi-structured questionnaire addressed questions on socioeconomic and specific issues related to homegardens, such as regarding the species found in the area, use purposes, form of maintenance, and size of the homegarden. The use value (UV) of the species was calculated to list the local importance of the plants according to informants. Sixty-two plants were recorded, among which, it was possible to identify 51 species, 46 genera and 29 families. The results showed there are sociocultural relationships between the people and the plants in the study area, involving the knowledge and use of plant species, economic aspects, resulting in the sale of surplus resources, both plants and animals raised in these areas; and ecological aspects, comprising the cultivation and management of native and/or exotic species. The data presented here may be used for conservation strategies and sustainability of plant resources.
\end{abstract}

Keyword: Agrosystems; Ethnobotany; Conservation unit.
(1) $0000-0002-9657-5671$

Vandermond do

Nascimento Gonçalves

D) 0000-0003-2173-8314

Bartolomeu Israel de Souza

(D) $0000-0003-4775-7775$

Reinaldo Farias Paiva de Lucena

\section{Introdução}

Os quintais rurais ou domésticos encontram-se situados em áreas particulares no entorno de residências exercendo a função de reservatórios de biodiversidade em comunidades espalhadas pelo mundo (Oakley, 2004; Gbedomon et al., 2017; Hoogesteger van Dijk et al., 2017; Shen et al., 2017). Dentre os sistemas organizacionais desenvolvidos nesses espaços tem-se o modelo de Quintal Agroflorestal (QAF) caracterizado como um tipo de Sistema Agroflorestal (SAF), o qual representa uma prática tradicional de uso da terra desenvolvida por famílias residentes em zonas rurais, periurbanas e urbanas (Almeida e Gama, 2014). Esses espaços são de grande importância para as populações locais, pois na maioria das vezes, as espécies ali encontradas são utilizadas e manejadas para fins de subsistência, sendo o produto excedente comercializado no intuito de aumentar a fonte de renda familiar (Kumar e Nair, 2004; Florentino et al., 2007; Guarim Neto e Amaral, 2010; Damaceno e Lobato, 2019).

Nestes sistemas as espécies agrícolas e florestais, bem como pequenos animais de baixo nível de insumos, são consorciadas no mesmo espaço e/ou tempo (Quaresma et al., 2015) buscando aperfeiçoar o uso dos recursos naturais. Cada quintal possuirá particularidades, seja referente às delimitações, estratégia de manejo ou finalidade de uso do recurso cultivado, assim as características encontradas são 
próprias de cada localidade (Guarim Neto e Amaral, 2010) e dinâmica desenvolvida pelo mantenedor. Esses critérios são importantes para otimização da cultura administrada na área do quintal. Novais et al. (2011) evidenciam que o entendimento de tais aspectos assume importância atual por se tratar de locais de conservação e demonstração de saberes acumulados através de gerações.

Desta forma, a fim de compreender o vinculo existente entre o ser humano e os recursos naturais vêm sendo desenvolvidas pesquisas no campo da etnobiologia, capazes de apontar os aspectos que envolvem essa conexão. Voltado para a inter-relação entre as populações humanas e recursos vegetais esses estudos são desenvolvidos pela etnobotânica, ciência que se norteia em compreender a dinâmica cultural e intelectual do conhecimento, uso e extração de espécies botânicas, podendo seus resultados contribuir para administração sustentável dos recursos (Sousa et al., 2015) e consequentemente conservação das espécies envolvidas.

Lucena et al. (2018) apontam que o uso de espécies de plantas por diferentes atores sociais para diversas finalidades apresenta grande importância para a sociedade e a manutenção desse saber milenar. Ao longo dos anos pesquisas que envolvem o conhecimento etnobotânico vem revelando que os vegetais são utilizados pelas pessoas para inúmeros fins utilitários, por exemplo, recurso alimentar, medicinal, veterinário, ornamental, tecnológico, construção e mágico-religioso, estendendo-se desde usos madeireiros a usos não madeireiros (Phillips e Gentry, 1993a; Phillips e Gentry, 1993b; Albuquerque e Andrade, 2002a; Albuquerque e Andrade, 2002b; Albuquerque et al., 2005b; Cunha et al., 2006; Lucena et al., 2007; Roque et al., 2010; Lucena et al., 2012; Lucena et al., 2017; Alves et al., 2017; Nunes et al., 2018; Silva et al., 2018). Para isso, a forma de coletada ou manejo ocorre de acordo com uso ao qual o coletor relacionará o recurso, como evidenciado na literatura (Lins et al., 2012; Lucena et al., 2015).

Dentre os biomas brasileiros que apresentam muitas pesquisas voltadas para o conhecimento tradicional, uso e manejo das plantas, estão a Caatinga e a Mata Atlântica, em virtude da presença dos principais grupos de pesquisa sobre a temática (Ritter et al., 2015). Além deles, também encontramos pesquisas desenvolvidas na Floresta Amazônica (Almeida et al., 2014; Ribeiro et al., 2017) e Cerrado (Franco e Barros, 2006; Ribeiro et al., 2017).

Referente às abordagens etnobotânicas já desenvolvidas, alguns estudos têm sido conduzidos em quintais rurais (Vieira et al., 2012; Carvalho et al., 2013; Figueiredo Júnior et al., 2013; Pereira et al., 2016; Spiller et al., 2016; Abreu et al., 2017; Silva et al., 2017) verificando o envolvimento que os atores sociais tem com os recursos vegetais cultivados na área, cuidados atribuídos ao mesmo e sua estrutura, a fim de denominá-los ou não como quintal agroflorestal. Bem como, apontando a utilização desse tipo de pesquisa como subsídio na gestão socioambiental em áreas de conservação (Prado et al., 2019). Porém, se faz necessário o aumento de análises para áreas que ainda não foram pesquisadas, buscandose estabelecer 0 vínculo entre 0 conhecimento popular e científico, tendo em vista sua importância social, cultural e econômica.

Neste contexto, a presente pesquisa foi desenvolvida na comunidade rural Brasileira localizada na Zona de Amortecimento do Parque Nacional de Sete Cidades (PNSC), área que não apresenta estudo voltado para o conhecimento acerca de cuidados destinados as espécies de plantas cultivadas no entorno de propriedades rurais pelas pessoas que ali residem. Cabe ressaltar que para essa comunidade, Nunes (2019) apontou o uso de diversas espécies botânicas ( $\mathrm{n}=$ 
33 spp) na prática medicinal tradicional. o PNSC está localizado no estado do Piauí composto com maior representatividade na região Nordeste do Brasil pelo bioma Cerrado (Ribeiro e Walter, 1998), ocupando cerca de 12 milhões de hectares dos quais 70,4\% estão em sua área de domínio e 29,6\% em sua área de transição (CEPRO, 1992).

No Estado do Piauí a vegetação recebe influência de três domínios florísticos: amazônico, caatingas e cerrados (Ducke e Black, 1953; Emperaire, 1985). A criação do PARNA foi efetivada levando em consideração seu reconhecimento enquanto nicho prioritário para a conservação da biodiversidade dos biomas Cerrado e Caatinga (Cavalcante, 2013). Essa magnitude ambiental propicia as pessoas residentes em sua proximidade um contato cultural e socioambiental com os recursos disponíveis, revelando a necessidade de pesquisas com essa perspectiva na localidade.

Diante do exposto, o presente estudo objetivou registrar 0 conhecimento, uso e importância de espécies vegetais na comunidade rural Cachoeira, além de apontar as estratégias que envolvem a dinâmica desenvolvida por mantenedores de quintais no cultivo dessas plantas, podendo ou não caracterizar esses espaços como um possível sistema do tipo agroflorestal.

\section{Material e métodos}

\section{Área de estudo}

A pesquisa foi conduzida na comunidade rural Cachoeira localizada no município Brasileira, Piauí, Nordeste do Brasil. Localidade que junto ao Município de Piracuruca delimitam a área do Parque Nacional das Sete Cidades (Figura 1).

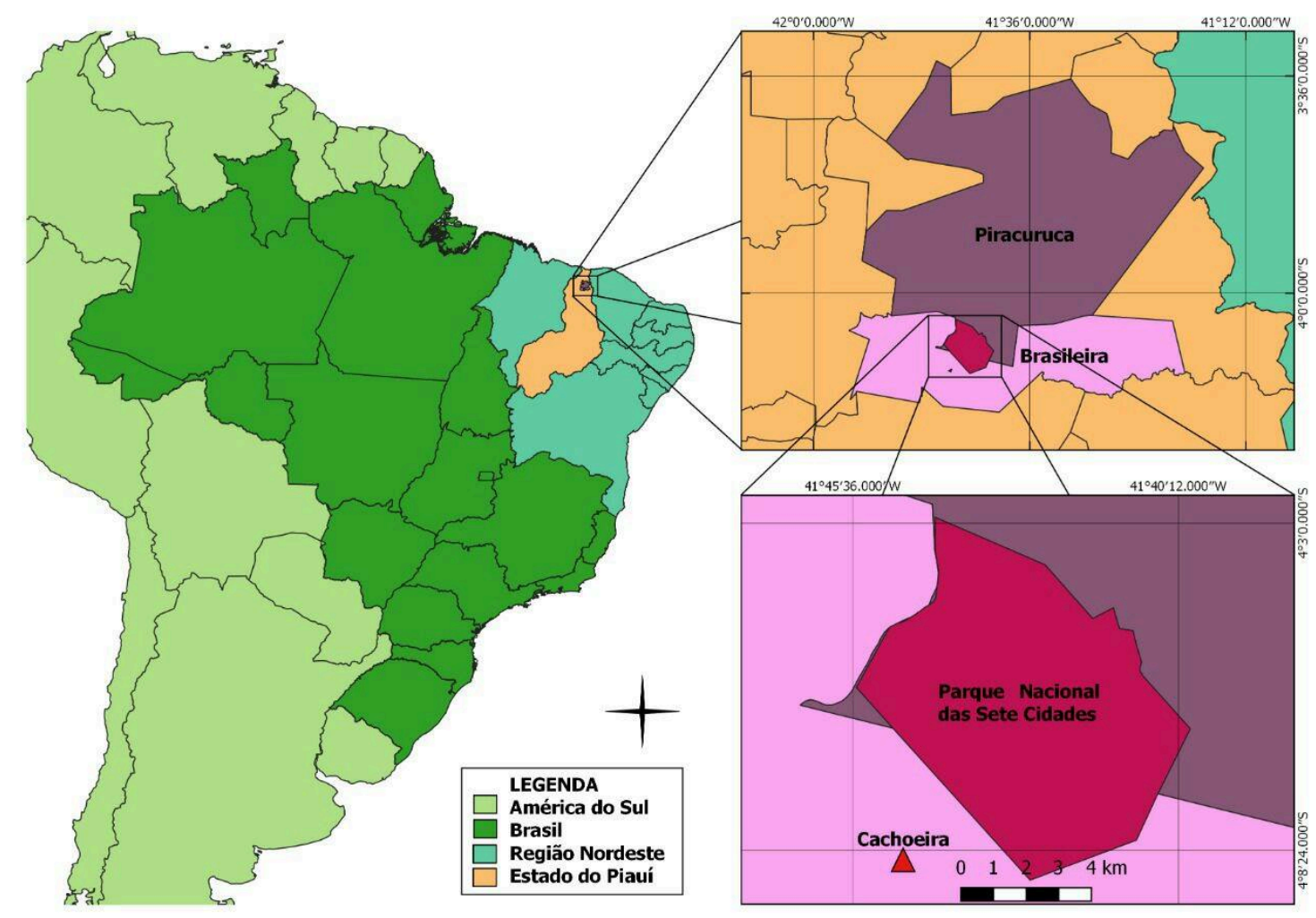

Figura 1. Localização da Comunidade Cachoeira, localizada no Município Brasileira no Estado do Piauí, Nordeste do Brasil. Mapa: Ezequiel da Costa Ferreira (2019). 
O Município Brasileira localizase sob as coordenadas geográficas $4^{\circ} 7^{\prime}$ 51" S, W 41 46' 55" (Geohack, 2019). Possui população estimada em 7.966 pessoas, com densidade demográfica de $9,04 \mathrm{hab} / \mathrm{km}^{2}$ (IBGE, 2010). Apresenta precipitação média anual de 1557,8 mm e a temperatura média anual de $26,5^{\circ} \mathrm{C}$ (Oliveira et al., 2017).

A comunidade Cachoeira está inserida na Zona de Amortecimento do Parque Nacional das Sete Cidades, dista aproximadamente $4 \mathrm{~km}$ da entrada sul do parque. 0 cuidado com a saúde dá-se através de visitas periódicas de agentes de saúde, existindo também na comunidade uma Unidade Básica de Saúde para atendimento de rotina com o clínico geral (Figura 2). Para o acesso a Educação Primária os estudantes se deslocam até as Instituições de Ensino presentes no Município de Brasileira, a prefeitura disponibiliza transporte para o translado.

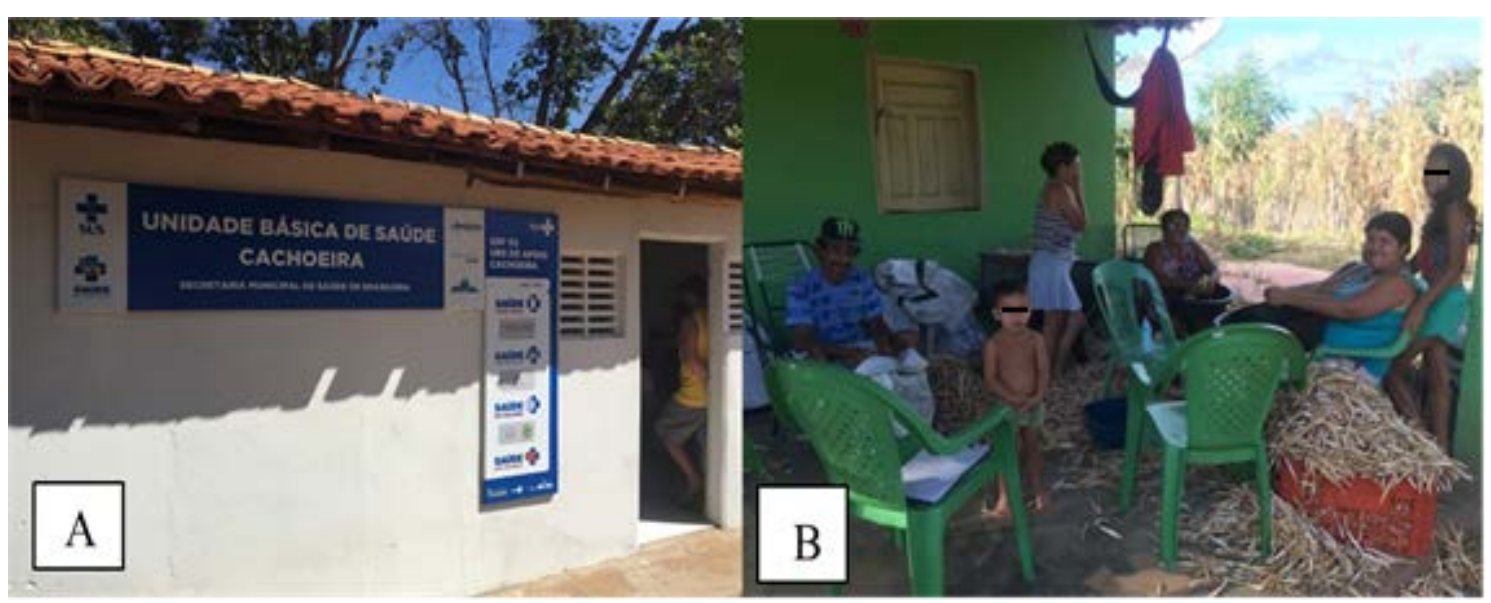

Figura 2. A - Unidade básica de saúde presente na zona rural e B - Mantenedores em atividade diária desenvolvida em quintais, presentes na comunidade Cachoeira, localizada no município Brasileira no estado do Piauí, Nordeste do Brasil.

A renda das famílias presentes nessa localidade é baseada na agricultura de subsistência, destacando-se o cultivo de feijão e milho, caprinocultura e suinocultura em seus quintais e/ou nos arredores da comunidade (Figura 2). Complementando a economia alguns moradores trabalham em na zona urbana do município Brasileira, outros são aposentados (as).

\section{Obtenção e análise dos dados}

Para realização do estudo foram visitadas todas as residências da comunidade Cachoeira (20 residências), porém as entrevistas foram realizadas apenas com 17 mantenedores de quintais, pois a ausência do chefe do lar nas demais moradias (3 residências) impossibilitou a realização da mesma, totalizando 17 informantes (9 homens e 8 mulheres), um por domicilio. A pesquisa foi desenvolvida no período de maio a setembro de 2018.

Inicialmente foi explicado a cada pessoa sobre a pesquisa, em seguida os atores sociais foram convidados a assinar o Termo de Consentimento Livre e Esclarecido, solicitado pelo Conselho Nacional de Saúde por meio do Comitê de Ética em Pesquisa (Resolução no 466/2012). Sendo o estudo aprovado pela Universidade Federal da Paraíba, registrado como CAAE 
99748618.0.0000.5188, parecer número 2.987.341.

Os dados foram obtidos por meio de formulários semiestruturados, complementados por entrevistas livres e conversas informais (Huntington, 2000; Albuquerque et al., 2010). 0 formulário utilizado abordou tanto questões sobre o perfil socioeconômico da população (Tabela 1), quanto perguntas específicas relacionadas aos quintais presentes na residência de cada mantenedor, espécies encontradas na área, finalidades de uso, parte(s) utilizada(s), modo de manutenção e tamanho do quintal, por exemplo.

Tabela 1. Perfil sócio econômico dos 17 entrevistados na comunidade Cachoeira, localizada no Município Brasileira, no Estado do Piauí, Nordeste do Brasil.

\begin{tabular}{lc}
\hline Aspecto socioeconômico & Número de entrevistados \\
\hline Sexo & 9 \\
Masculino & 8 \\
Feminino & 7 \\
Faixa etária & 5 \\
$21-50$ & 5 \\
$51-80$ & \\
Não declarado & 3 \\
Tempo de moradia & 10 \\
$<10$ anos & 3 \\
$11-40$ anos & 1 \\
$41-70$ anos & \\
Não declarado & \\
\hline
\end{tabular}

Os nomes vernaculares das espécies citadas foram registrados de acordo com a citação dos informantes e levados em consideração para inferir a nomenclatura científica.

Para identificação da flora foi realizado registros fotográficos de alguns indivíduos, levantamento da nomenclatura das espécies evidenciadas em estudos botânicos e etnobotânicos previamente realizados na mesorregião da pesquisa, e quando possível foi realizada a coleta e herborização em campo de materiais biológicos, os quais foram identificados e incorporados no Herbário Jaime Coelho de Morais (EAN) do Centro de Ciências Agrárias (CCA) da Universidade Federal da Paraíba (UFPB).

0 valor de uso (VU) das espécies foi calculado a fim de quantificar a importância local das plantas na visão dos entrevistados, através da fórmula (modificada por Rossato et al., 1999):

$$
\mathbf{V U}=\mathbf{U i} / \mathbf{n}
$$

Onde:

$\mathrm{VU}=$ valor de uso da espécie;

Ui = número de citações de uso da espécie mencionada por cada informante;

$\mathrm{n}=$ número total de informantes.

0 critério nativo/exótica foi estabelecido regionalmente, ou seja, em nível de Nordeste, seguindo a classificação adotada pelo Jardim Botânico do Rio de Janeiro (Forzza et al., 2010). 


\section{Resultados e discussão}

\section{Conhecimento e uso dos recursos vegetais}

Foram registradas 62 plantas, sendo identificadas 53 espécies, 47 gêneros e 30 famílias. A família mais expressiva foi a Fabaceae, apresentando seis espécies, seguida de Anacardiaceae e Poaceae, ambas com quatro espécies
(Figura 3). Algumas pesquisas etnobotânicas têm destacado a família Fabaceae por apresentar maior representação em riqueza de espécies (Silva e Andrade, 2005; Franco e Barros, 2006; Lima et al., 2016; Pereira et al., 2018), inclusive em áreas de quintais rurais no município do Piauí (Pereira et al., 2016; Silva et al., 2017), evidenciando sua importância para as populações locais.

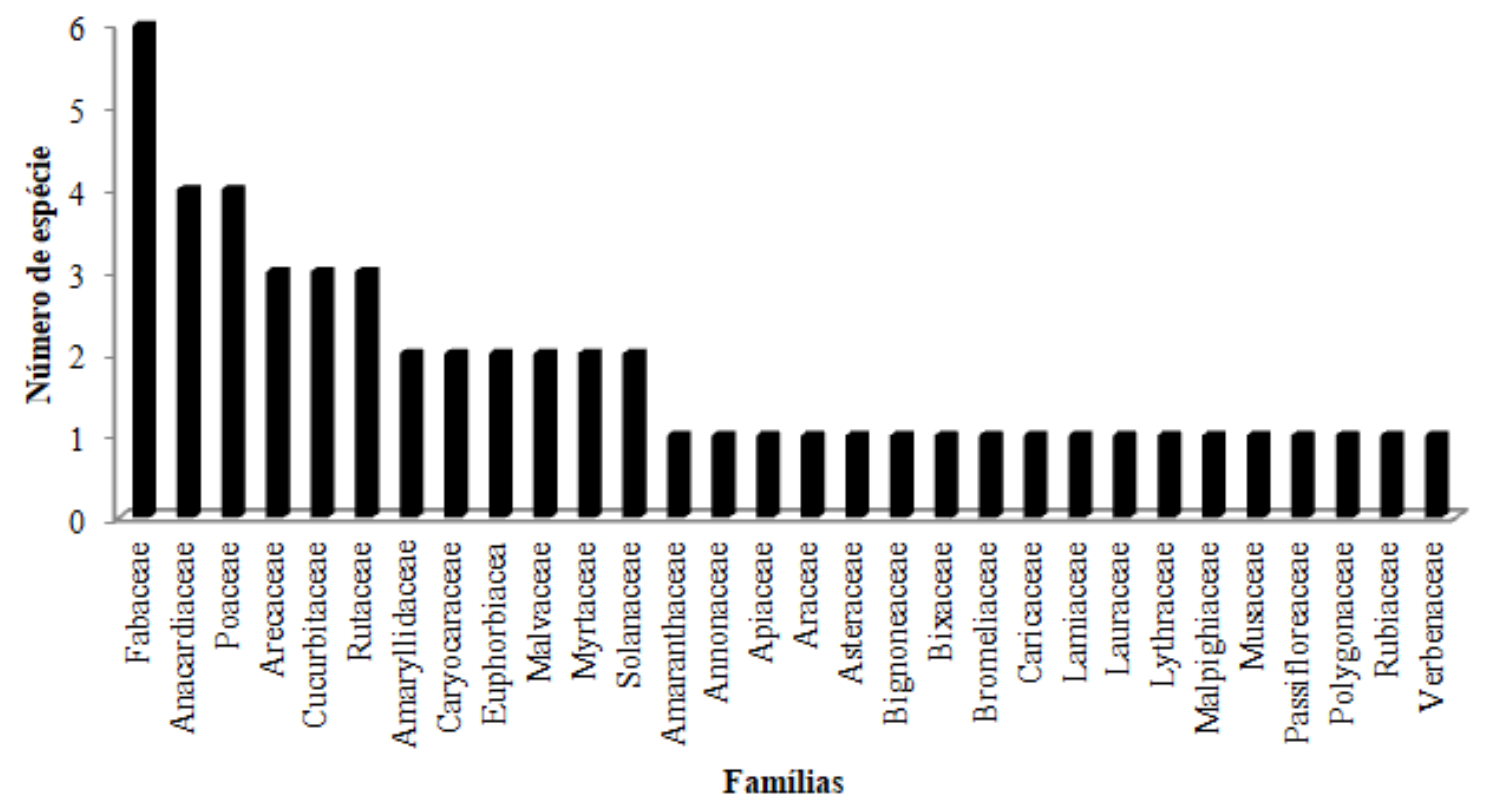

Figura 3. Número de espécies distribuído em famílias botânicas presentes em quintais da comunidade Cachoeira, localizada no município Brasileira no estado do Piauí, Nordeste do Brasil.

A maior parte das plantas presentes nos quintais estudados é de origem exótica com registro de 27 espécies, as demais são silvestres $(21$ spp.), corroborando com a tendência encontrada por Silva et al. (2017) no estado do Piaui. Das plantas identificadas em nível espécie e que foi possível descrever o hábito ( $\mathrm{n}=49)$, tem-se 40,82\% com hábito arbóreo, 26,53\% herbáceo, 24,49\% arbustivo, 6,12\% subarbustivo e $2,04 \%$ trepadeira.

As espécies foram atribuídas para fins de alimentação (36 spp.), medicinal (19 spp.), ornamental (9 spp.) e forragem (7 spp.), e algumas são citadas para mais de uma finalidade (Tabela 2). Essas categorias utilitárias se mostram representativas tratando-se de estudos em quintais urbanos e rurais (Carniello et al., 2010; Silva et al., 2017; Pereira et al., 2018), não contemplando a utilização madeireira bastante citada em pesquisas que envolvem o uso de espécies fora desses espaços (Ribeiro et al., 2014a; Ribeiro et al., 2014b; Lucena et al., 2017).

As partes das plantas que obtiveram maior número de citações foram o fruto (99 citações), folha (51 citações), semente (20 citações), raiz (9 citações), caule (5 citações) e casca (corte realizado no caule) (1 citação). Ainda em 
relação às partes vegetativas, na alimentação (36 spp.) apenas o caule não é utilizado, e na categoria forragem (7 spp.) as partes utilizadas são a folha (7 citações) e semente (3 citações). Para fins ornamentais (9 spp.) são atribuídos usos ao caule (3 citações) e folha (9 citações). No uso medicinal (19 spp.) as partes utilizadas são folha (27 citações), fruto (1 citação) e casca (1 citação).

Sobre o modo de preparo, o fruto pode ser consumido de diversas formas: em in natura ou através do preparo de suco (exemplo Malpighia glabra), no preparo de vitamina (ex. Citrus sp. 2), chá (ex. Morinda citrifolia), elaboração de temperos (ex. Capsicum sp. e Bixa orellana), cozido (ex. Cucurbita sp.) ou associado em garrafada (ex. Anacardium humile). Referente à utilização da folha, é comum ser feito chá (ex. Lippia alba) e preparo de tempero (ex. Coriandrum sativum e Allium sp.), quanto a semente são utilizadas in natura (Zea mays) ou cozida (ex. Phaseolus sp.). A raiz é preparada através de seu cozimento (ex. Manihot esculenta), o caule consumido in natura (ex. Saccharum officinarum) e a casca da planta é utilizada para se fazer chá.

Os valores de uso das espécies citadas variaram entre 0,06 e 0,76 , as espécies com maior representatividade foram: Anacardium occidentale (caju) $(\mathrm{VU}=0,76), Z$. mays (milho) $(\mathrm{VU}=0,65)$, Citrus sp. 2 (laranja) (VU = 0,59). A maior parte dos recursos vegetais (recursos provenientes de 34 spp.) apresentou valor de uso baixo $(\mathrm{VU}=0,06)$ (Tabela 2$)$. Cabe evidenciar que além das espécies descritas como de maior valor utilitário, as espécies Mangifera indica L. (manga), Phaseolus sp. (feijão), Citrus sp. 1 (limão) (ambas presentes em oito quintais) e Malpighia glabra L. (acerola) (sete quintais) também foram evidenciadas em um número representativo de quintais (Tabela 2).

De forma geral as plantas que apresentaram maior valor utilitário para os mantenedores são de origem exótica, porém também ocorre o uso de espécies nativas. Nesse tocante, apesar da incidência de espécies silvestres serem em menor proporção, os quintais seria uma possível forma de preservar espécies endêmicas e de importância cultural, bem como manejar sustentavelmente os recursos úteis em diferentes áreas. Essa questão de âmbito conservacionista foi elencada por Florentino et al. (2007), que avaliando a importância do quintal, em uma área de Caatinga, notou redução na pressão de uso da vegetação nativa através do cultivo de espécies lenhosas para fins madeireiros.

Os quintais rurais e as estratégias de manutenção desenvolvidas nesses espaços

Foram visitados 17 quintais rurais, onde 12 apresentam algumas características de quintais agroflorestais (consorcio de culturas, por exemplo). Esse sistema de produção agregam espécies arbóreas florestais com elementos agrícolas anuais, podendo haver ou não a criação de espécies animais de maneira simultânea, no mesmo espaço e/ou tempo (Dubois, 2008). Dessa forma, 11 quintais visitados desenvolvem o modelo Agrossilvopastoril caracterizado pelo consórcio entre cultivo de animais, agricultura e manutenção de plantas nativas, e um deles como sistema Silviagrícola, pois desenvolvia apenas o cultivo de espécies locais e agrícolas (Q5).

No que se refere ao critério de escolha em plantar as espécies vegetais foi observado que 36 plantas são cultivadas por terem valor utilitário como o alimentar, categoria de maior representatividade, além de demais atribuições de uso (forragem e ornamentação, por exemplo). Contudo, outras características também foram aferidas pelos informantes, por exemplo, facilidade de ser plantada e de administração/manejo (Figura 4.A), questões culturais (gostar de plantar), aproveitamento do espaço, aumento na renda familiar e algumas espécies estão 
presentes na região, sendo possível colheita e plantio no espaço.

Outra motivação para a criação se dá pelo apego emocional com determinados indivíduos. Assim, em relação aos animais domésticos criados nesses espaços têm-se bovinos, caprinos, suínos e aves (Gallus gallus domesticus galinha, Meleagris gallopavo - peru, Anseriformes - patos e Numida meleagris - capote), que ora são destinados ao consumo dos proprietários, ora a venda em localidades próximas, com a finalidade de aumentar a renda mensal.

Tabela 2. Espécies botânicas cultivadas em quintais rurais por moradores da comunidade rural de Cachoeira, localizada no munícipio Brasileira, Piauí, Nordeste do Brasil. Convenções: $0=$ Origem: na = nativa, ex = exótica; $\mathrm{H}$ = Hábito: arv = árvore, erv = erva, arb = arbusto, sub = subarbusto e trep = trepadeira; $\mathrm{CU}=$ Categorias de Uso: al = alimentação, med = medicinal, orn = ornamentação, for = forragem; VU = Valor de Uso. Os números na coluna "Quintais" representa cada unidade amostral.

\begin{tabular}{|c|c|c|c|c|c|c|}
\hline Família/Nome científico & Nome vernacular & $\mathbf{0}$ & $\mathbf{H}$ & $\mathbf{C U}$ & VU & Quintais \\
\hline \multicolumn{7}{|l|}{ Amaranthaceae } \\
\hline $\begin{array}{l}\text { Dysphania ambrosioides } \\
\text { Mosyakin \& Clemants }\end{array}$ & Mastruz & ex & erv & med & 0,08 & 8 \\
\hline \multicolumn{7}{|l|}{ Amaryllidaceae } \\
\hline Allium cepa L. & Cebola & ex & erv & al & 0,12 & 4,15 \\
\hline Allium sp. & Cebolinha & ex & erv & al & 0,06 & 9 \\
\hline \multicolumn{7}{|l|}{ Anacardiaceae } \\
\hline Anacardium humile A. St. -Hil. & Cajuí & na & arv & al & 0,06 & 5 \\
\hline Anacardium occidentale L. & Caju & na & arv & al & 0,76 & $\begin{array}{c}3,4,5,6,7 \\
8,9,11,13 \\
15,17\end{array}$ \\
\hline Mangifera indica $\mathrm{L}$. & Manga & ex & arv & al & 0,47 & $\begin{array}{c}4,5,7,9,11 \\
13,15,17\end{array}$ \\
\hline Spondias purpurea L. & Seriguela & ex & arv & al & 0,23 & $4,9,15,16$ \\
\hline \multicolumn{7}{|l|}{ Annonaceae } \\
\hline Annona squamosa L. & Ata & na & arv & al, med & 0,18 & $4,6,7$ \\
\hline \multicolumn{7}{|l|}{ Apiaceae } \\
\hline Coriandrum sativum L. & Coentro & ex & erv & $\mathrm{al}$ & 0,06 & 15 \\
\hline \multicolumn{7}{|l|}{ Araceae } \\
\hline Dieffenbachia sp. & $\begin{array}{l}\text { Comigo-ninguém- } \\
\text { pode }\end{array}$ & na & erv & orn & 0,06 & 17 \\
\hline \multicolumn{7}{|l|}{ Arecaceae } \\
\hline Cocos nucifera L. & Coco & ex & arv & al & 0,18 & $4,5,9$ \\
\hline $\begin{array}{l}\text { Bactris cf. campestris Poepp. ex } \\
\text { Mart. }\end{array}$ & Tucum & na & arv & for & 0,06 & 14 \\
\hline Mauritia flexuosa L. f. & Buriti & na & arv & $\mathrm{al}$ & 0,06 & 4 \\
\hline \multicolumn{7}{|l|}{ Asteraceae } \\
\hline Helianthus annuus L. & Girassol & ex & erv & orn & 0,06 & 6 \\
\hline \multicolumn{7}{|l|}{ Bignoneaceae } \\
\hline Tabebuia sp. & Pau d'arco & na & arv & for, al & 0,12 & 7,14 \\
\hline \multicolumn{7}{|l|}{ Bixaceae } \\
\hline Bixa orellana $\mathrm{L}$. & Urucum & na & arb & al & 0,23 & $4,5,6,9$ \\
\hline \multicolumn{7}{|l|}{ Bromeliaceae } \\
\hline Ananas comosus (L.) Merr. & Abacaxi & na & erv & al & 0,06 & 7 \\
\hline
\end{tabular}


Tabela 2. Continuação.

\begin{tabular}{|c|c|c|c|c|c|c|}
\hline Família/Nome científico & Nome vernacular & $\mathbf{0}$ & $\mathbf{H}$ & $\mathbf{C U}$ & VU & Quintais \\
\hline \multicolumn{7}{|l|}{ Caricaceae } \\
\hline Carica papaya L. & Mamão & na & $\operatorname{arv}$ & al & 0,35 & $\begin{array}{c}4,9,12,13 \\
15,16\end{array}$ \\
\hline \multicolumn{7}{|l|}{ Caryocaraceae } \\
\hline Caryocar cuneatum Wittm & Piqui & na & arv & med & 0,08 & 11 \\
\hline Caryocar sp. & Piquiá & na & arv & orn & 0,06 & 8 \\
\hline \multicolumn{7}{|l|}{ Cucurbitaceae } \\
\hline $\begin{array}{l}\text { Citrullus lanatus (Thunb.) } \\
\text { Matsum. \& Nakai }\end{array}$ & Melancia & ex & erv & al & 0,29 & $1,4,5,7,12$ \\
\hline Cucumis anguria $\mathrm{L}$. & Maxixe & ex & erv & al & 0,18 & $4,7,12$ \\
\hline Cucurbita sp. & Abóbora & ex & erv & al & 0,36 & $\begin{array}{c}1,2,4,5,7 \\
12\end{array}$ \\
\hline \multicolumn{7}{|l|}{ Euphorbiacea } \\
\hline Euphorbia sp. & Cabeça de velho & - & - & orn & 0,06 & 4 \\
\hline Manihot esculenta Crantz. & Macaxeira & na & $\operatorname{arv}$ & al & 0,35 & $\begin{array}{l}1,10,11 \\
12,13,17\end{array}$ \\
\hline \multicolumn{7}{|l|}{ Fabaceae } \\
\hline Dinizia excelsa Ducke & Angelim & - & - & for & 0,06 & 11 \\
\hline Hymenaea courbaril L. & Jatobá & na & arv & for, med & 0,12 & 8,14 \\
\hline $\begin{array}{llll}\begin{array}{l}\text { Libidibia } \\
\text { Queiroz }\end{array} & \text { ferrea } & \text { (Mart.) } & \text { L.P. } \\
\end{array}$ & Jucá & na & $\operatorname{arv}$ & med & 0,08 & 8 \\
\hline Parkia platycephala Benth. & Faveira & na & arv & for & 0,06 & 11 \\
\hline Phaseolus sp. & Feijão & - & sub & al & 0,47 & $\begin{array}{c}1,2,4,5,7 \\
8,10,12 \\
\end{array}$ \\
\hline Tamarindus indica L. & Tamarina & ex & arv & al & 0,12 & 6,9 \\
\hline \multicolumn{7}{|l|}{ Lamiaceae } \\
\hline Plectranthus sp. & Boldo & ex & arb & med & 0,06 & 9 \\
\hline \multicolumn{7}{|l|}{ Lauraceae } \\
\hline Persea americana Mill. & Abacate & ex & arv & al & 0,06 & 7 \\
\hline \multicolumn{7}{|l|}{ Lythraceae } \\
\hline Punica granatum L. & Romã & ex & arb & med & 0,08 & 6 \\
\hline \multicolumn{7}{|l|}{ Malpighiaceae } \\
\hline Malpighia glabra L. & Acerola & na & arb & al & 0,41 & $\begin{array}{c}4,5,6,7,9 \\
15,16\end{array}$ \\
\hline \multicolumn{7}{|l|}{ Malvaceae } \\
\hline $\begin{array}{l}\text { Abelmoschus esculentus } \\
\text { Moench }\end{array}$ & Quiabo & ex & arb & al & 0,12 & 4,9 \\
\hline Gossypium sp. & Algodão & ex & arb & al, orn & 0,23 & $4,8,15,16$ \\
\hline \multicolumn{7}{|l|}{ Musaceae } \\
\hline Musa paradisiaca $\mathrm{L}$. & Banana & ex & arb & al & 0,35 & $\begin{array}{c}4,9,7,11 \\
13,17\end{array}$ \\
\hline \multicolumn{7}{|l|}{ Myrtaceae } \\
\hline Campomanesia sp. & Guabiraba & na & arv & for & 0,06 & 8 \\
\hline Psidium guajava L. & Goiaba & na & arv & al & 0,23 & $4,6,13$ \\
\hline \multicolumn{7}{|l|}{ Passifloreaceae } \\
\hline Passiflora sp. & Maracujá & na & trep & al & 0,06 & 12 \\
\hline \multicolumn{7}{|l|}{ Poaceae } \\
\hline $\begin{array}{l}\text { Cymbopogon cf. nardus } \\
\text { Rendlei }\end{array}$ & Capim de cheiro & ex & erv & med & 0,06 & 11 \\
\hline Cymbopogon citratus (DC.) Stapf & Capim santo & ex & erv & med & 0,06 & 12 \\
\hline Saccharum officinarum L. & Cana de açucar & ex & arb & al & 0,18 & $5,11,13$ \\
\hline
\end{tabular}


Tabela 2. Continuação.

\begin{tabular}{|c|c|c|c|c|c|c|}
\hline Família/Nome científico & Nome vernacular & $\mathbf{0}$ & $\mathbf{H}$ & $\mathbf{C U}$ & VU & Quintais \\
\hline Zea mays $\mathrm{L}$. & Milho & ex & erv & for, al & 0,65 & $\begin{array}{c}1,2,4,5,7 \\
10,12,16\end{array}$ \\
\hline \multicolumn{7}{|l|}{ Polygonaceae } \\
\hline Coccoloba sp. & Costela de vaca & - & - & med & 0,06 & 4 \\
\hline \multicolumn{7}{|l|}{ Rubiaceae } \\
\hline Morinda citrifolia $\mathrm{L}$. & Noni & ex & arb & med & 0,08 & 9 \\
\hline \multicolumn{7}{|l|}{ Rutaceae } \\
\hline Citrus sp. 1 & Limão & ex & arb & med, al & 0,53 & $\begin{array}{l}4,5,6,7,8 \\
9,13,15\end{array}$ \\
\hline Citrus sp. 2 & Laranja & ex & arb & med, al & 0,59 & $\begin{array}{c}4,5,8,13 \\
16,17\end{array}$ \\
\hline Citrus reticulata Blanco & Tangerina & ex & arb & al & 0,06 & 6 \\
\hline \multicolumn{7}{|l|}{ Solanaceae } \\
\hline Capsicum sp. & Pimenta & - & - & al & 0,29 & $\begin{array}{c}4,9,12,15, \\
17\end{array}$ \\
\hline Solanum lycopersicum L. & Tomate & na & sub & al & 0,06 & 15 \\
\hline \multicolumn{7}{|l|}{ Verbenaceae } \\
\hline $\begin{array}{l}\text { Lippia alba (Mill.) N.E. Br. ex } \\
\text { Britton \& P. Wilson }\end{array}$ & Cidreira & ex & sub & al, med & 0,35 & $\begin{array}{c}6,7,9,12 \\
15,16\end{array}$ \\
\hline \multicolumn{7}{|l|}{ Não identificadas } \\
\hline & Amargosa & - & - & orn & 0,06 & 3 \\
\hline & Batata & - & - & al & 0,06 & 11 \\
\hline & Carrã & - & - & med & 0,06 & 11 \\
\hline & Ciarure & - & - & med & 0,06 & 4 \\
\hline & Condensa & - & - & med & 0,06 & 4 \\
\hline & Mamona & - & - & al & 0,06 & 5 \\
\hline & Repelente & - & - & $\begin{array}{l}\text { med, } \\
\text { orn }\end{array}$ & 0,59 & $\begin{array}{l}4,6,7,11, \\
12,13,14, \\
15,16,17\end{array}$ \\
\hline & Rabuja & - & - & orn & 0,06 & 8 \\
\hline & Vavaco & - & - & med & 0,08 & 9 \\
\hline
\end{tabular}

Esses animais são alimentados com recursos externos como a ração, mas também de produtos resultantes do cultivo das plantas que não tem utilidade para as pessoas, mas servem para alimentação dos animais. Na maior parte do tempo, os animais são mantidos presos para evitar que se alimentem das plantas que foram plantadas para a subsistência da família (Figura 4. B, C, D), podendo também serem soltos fora do espaço de cultivo.

Quanto à escolha do local ideal para plantarem as espécies botânicas no quintal, os informantes discorreram que devem ser áreas que tenha disponibilidade de água, presença de sol e ser uma terra fértil. Apenas cinco deles relataram que não há espaço específico, podendo ser plantadas em qualquer localidade, desde que não interfiram no deslocamento. Salienta-se que os fatores ambientais descritos são considerados preponderantes quando tratamos de Sistemas do tipo Agroflorestais, que quando implantados revelam-se eficientes diante de tais condições, refletindo em estratégias de cultivo desenvolvidas pela comunidade estudada. 


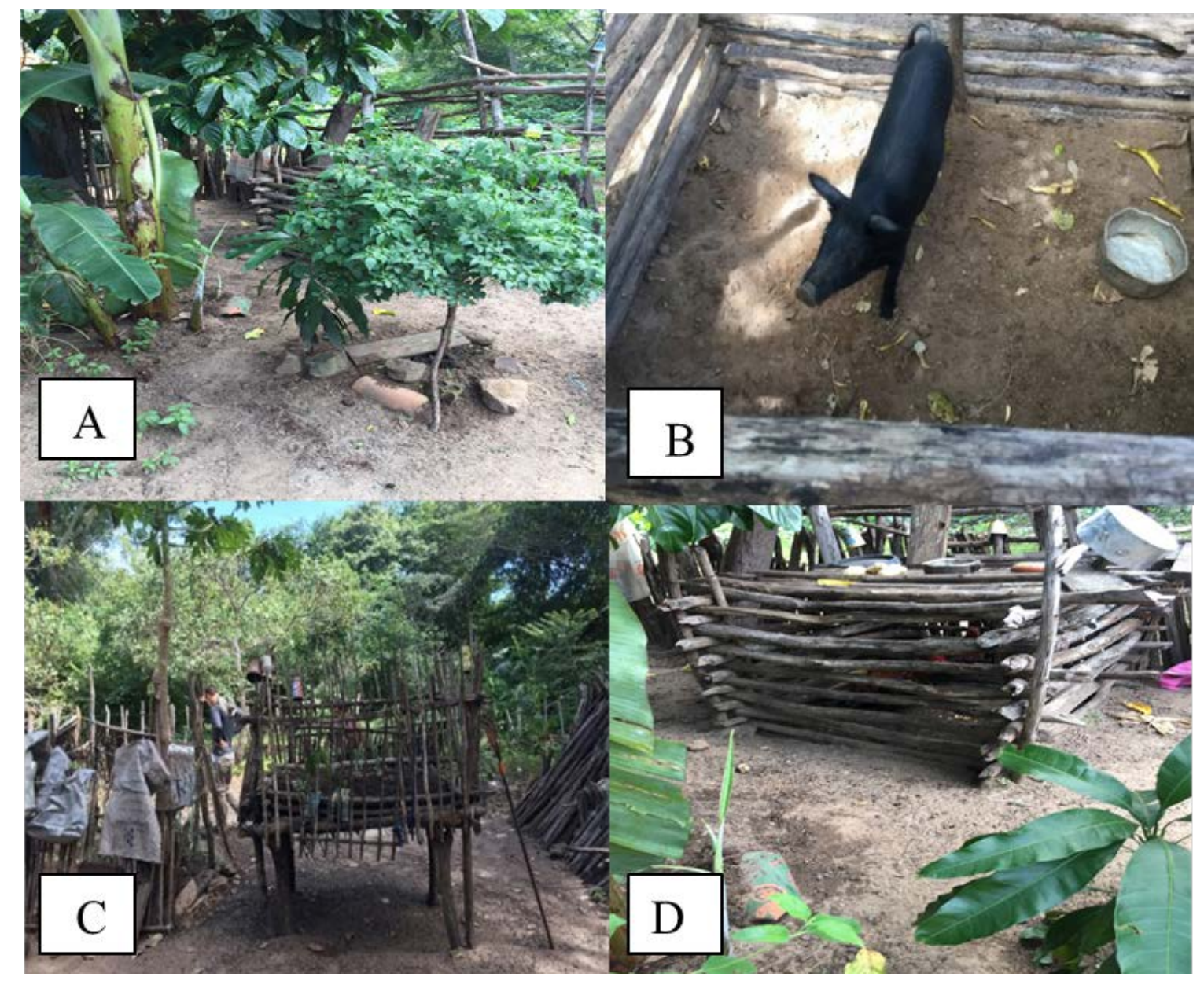

Figura 4. A - Estratégias para cultivo de espécies vegetais presentes em quintal rural; e B, C, D Cuidados realizados para criação de animais domésticos em espaços particulares no entorno de residências rurais, respectivamente desenvolvidos na comunidade Cachoeira, localizada no município Brasileira no estado do Piauí, Nordeste do Brasil.

Além disso, os mantenedores afirmam que produções de maior escala, como a de Phaseolus sp. (feijão) é realizada em espaço nomeado de "roçados", que em geral ficam localizados próximo às residências, mas que não compõem o espaço. Cabendo salientar que esse critério foi levado em consideração ao se analisar os tamanhos dos quintais visitados durante 0 desenvolvimento da pesquisa. Carvalho et al. (2013) e Guarim Neto e Amaral (2010) corroboram com o presente estudo ao apontarem em suas análises sobre quintais agroflorestais, em comunidades rurais, que a disposição das espécies nesses espaços, bem como as formas de manejo atribuídas as mesmas não segue um padrão global definido.

Dessa forma, o tamanho dos quintais na comunidade rural Cachoeira variou entre $50 \mathrm{~m}^{2}$ e 2.388,75 $\mathrm{m}^{2}$, apresentando número de espécies vegetais que variaram entre 8 e 27 (Figura 5) e entre 20 e 90 animais de sua propriedade, a depender do mantenedor. Em relação a essa proporção de espaço dos quintais, estudos apontam não haver uma padronização de tamanhos e formatos dos mesmos, sendo registradas diversas estruturas (Albuquerque et al., 2005a; Carvalho et al., 2013, Vieira et al., 2012; Figueiredo Junior et al., 2013; Chitsondzo e Silva, 2013; Almeida e Gama, 2014). 


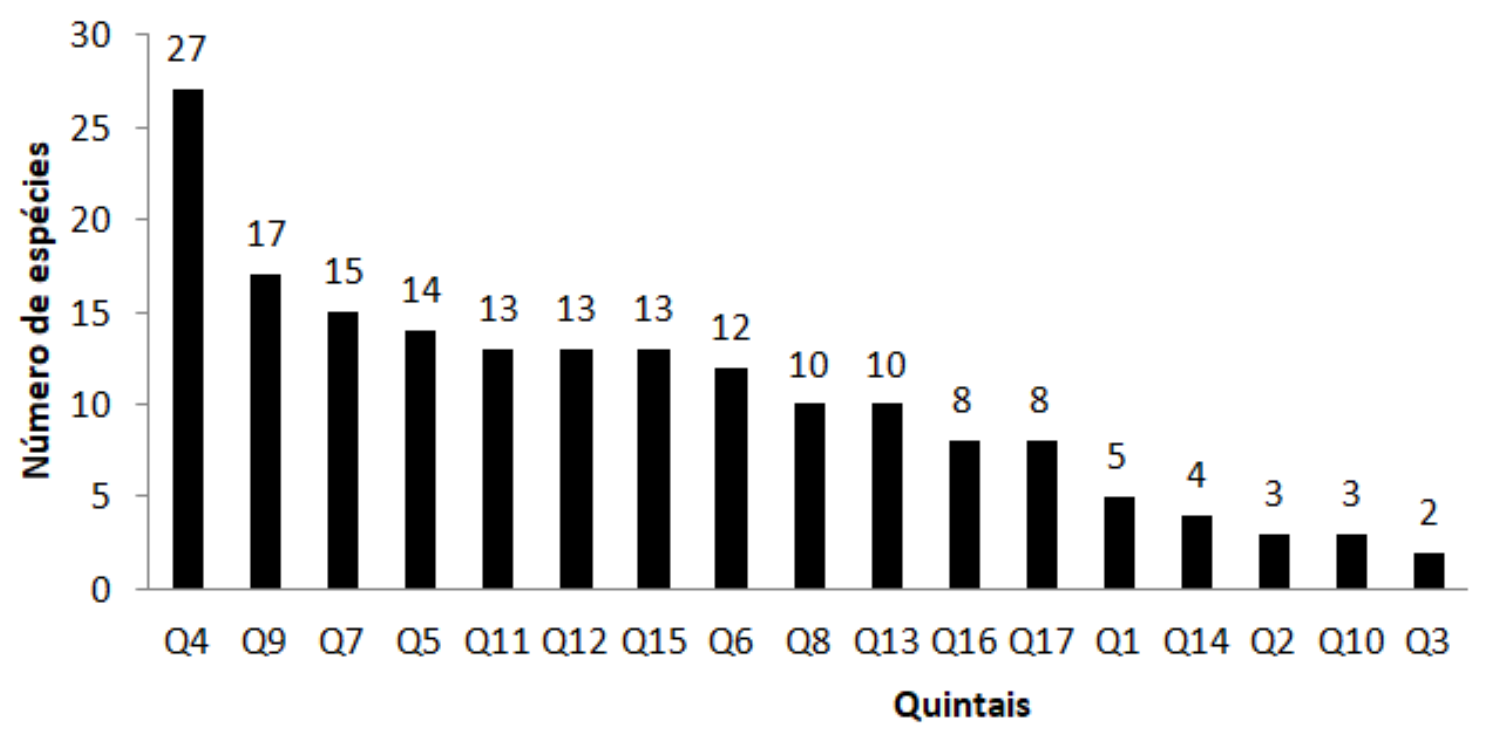

Figura 5. Número de espécies distribuídas em quintais da Comunidade Cachoeira, localizada no Município Brasileira, no Estado do Piauí, Nordeste do Brasil.

Alguns cuidados devem ser tomados para manter o quintal produtivo, assim, de acordo com os mantenedores, é realizada a limpeza periódica do espaço (varrer, roçar, capinar), irrigação e adubação (através da aplicação de estrume) (Figura 6). Essas ações podem ser consideradas eficientes, pois de acordo com Florentino et al. (2007) o desenvolvimento de estratégias de manejo é capaz de promover a otimização dos recursos naturais. Todavia, é importante ressaltar que segundo os informantes que essas atividades são desenvolvidas de maneira "inconsciente", através do conhecimento empírico transmitido de geração em geração por pessoas mais velhas ou observação particular.

No entanto, levando em consideração a necessidade de promover a sustentabilidade ambiental dos quintais através da agricultura familiar é necessário à adoção de um modelo de exploração consciente, capaz de garantir disponibilidade dos recursos ao longo do ano (Abdo et al. 2008). Nesse tocante, os Sistemas Agroflorestais se mostram como uma produção agrícola eficaz e eficiente, pois permitem fornecimento de diversos produtos (alimentares, medicinais, dentre outros), bem estar e saúde pública (umidade do ar, temperatura e poluição atmosférica), proteção dos solos e dos mananciais (Abdo et al., 2009), além de promoverem a fixação de carbono na biomassa (Castanho Filho, 2008).

Voltada a questões de caráter econômico, tendo em vista que alguns mantenedores afirmam comercializar os produtos excedentes a sua necessidade diária, atualmente algumas políticas públicas buscam dar suporte aos pequenos produtores rurais, por exemplo, o Programa Nacional de Fortalecimento da Agricultura Familiar (PRONAF) (1996) que intensificou o reconhecimento sobre as atividades agrícolas familiares por parte das instituições governamentais (Foguesatto et al., 2016), porém ainda se há necessidade de dar a esses atores sociais apoio e orientações técnicas cabíveis capaz de elevar a produção de insumos para seu autoconsumo e até mesmo no atendimento do mercado local. Os conhecimentos práticos, aliados ao conhecimento científico, dão uma grande 
contribuição na condução dos plantios (Abdo et al., 2008).

Referente ao processo de adubação desenvolvido na localidade, a ausência na utilização de insumos de alta periculosidade, substituído através da adubação orgânica, garante a essas pessoas uma prática sustentável que contribui com a preservação da natureza e maior segurança alimentar e nutricional considerando que os alimentos resultantes não são contaminados com substâncias químicas. Além disso, os sistemas agroflorestais podem contribuir com melhoramento da fertilidade do solo (Pinho et al., 2012) e captação de carbono (Araújo et al., 2013; Fernandes et al., 2018).

Quando indagados sobre a necessidade de mão de obra externa para auxiliar na manutenção dos quintais a maior parte dos entrevistados afirmam ser algo dispensável (13 informantes), isso porque os chefes de família (homens e mulheres) se dividem na realização das atividades que são desenvolvidas na localidade, contudo a maior parte das atribuições fica por conta das mulheres, refletindo em seu importante papel na manutenção dos quintais, algo já reportado em outras localidades (Pereira et al., 2018) que incluem também a contribuição de crianças que compõem a estrutura familiar.

Ainda em relação à figura feminina na agricultura familiar, boa parte dessas mulheres tende a não serem reconhecidas por seus serviços agrícolas, por exemplo, cuidados com pequenos animais (aves, gado de leite e suínos), cultivo e manutenção de hortas, sendo consideradas apenas como "ajuda" (Boni, 2006; Chaves et al., 2018) tratando-se de uma atividade de atuação doméstica (Galizoni e Ribeiro, 2004). Este fato da invisibilidade de seu potencial produtivo voltado para a atividade e consequentemente subestima sua participação econômica (Cordeiro, 2007).

A participação social de todos os componentes familiares somados ao pequeno tamanho mensurados nesses quintais e baixo investimento financeiro, tendo em vista que nem todos os agricultores são aposentados ou recebem algum incentivo do governo (como por exemplo, a bolsa família) faz dessas áreas um local de desenvolvimento de agricultura familiar.

Estas relações se tornam de grande relevância, pois a comunidade Cachoeira está localizada no entorno do Parque Nacional de Sete Cidades, uma unidade de conservação de proteção integral que deve manter-se ausente de exploração da biodiversidade. Assim, a prática de cultivar espécies em quintais apresenta-se como uma atividade primordial para a conservação ambiental, uma vez que esses sistemas permitem manter a biodiversidade local nessas áreas e faz com que as relações entre o ser humano e esses recursos sejam desenvolvidas restritamente à área, como discorrido pelos atores sociais visitados. Além disso, durante as conversas informais com os entrevistados percebeu-se que atividades de extrativismo eram comuns na unidade de conservação antes de sua implementação como área prioritária para conservação, reduzindo sua intensificação apenas após a fiscalização advinda de sua funcionalidade.

Neste tocante, a utilização de espécies exóticas e/ou nativas cultivadas em quintais rurais em maior escala é de extrema importância para funcionalidade eficiente da unidade, devendo esse fato ser levado em consideração por parte dos gestores da unidade. Sendo necessário que a área de conservação esteja ciente dessas atividades buscando incentiva-la, considerando sua importância para a mesma.

\section{Conclusão}

O estudo evidencia que a prática de cultivar plantas em espaços particulares como os quintais rurais é uma atividade comum na comunidade Cachoeira, sendo cultivadas espécies vegetais como, $A$. occidentale (caju), $Z$. 
mays (milho), Citrus sp. 2 e repelente (não identificada), de maiores relevância para os mantenedores de quintais, e criação de recursos animais, por exemplo bovinos, caprinos e suínos.

Nestes espaços são desenvolvidas estratégias voltadas para o consórcio de plantas e animais característicos de Sistemas Agroflorestais do tipo Silviagrícola e Agrossilvipastoril. Além de cuidados para a manutenção das áreas (limpeza, adubação e irrigação), ambos vislumbrando possibilitar maior produtividade e conservação dos recursos existentes. Outro ponto diz respeito à comercialização dos produtos excedentes a sua necessidade diária.

Contudo, a fim de realizar um diagnóstico preciso para este tipo de sistema são necessários estudos de aspecto fitossociológicos, que busquem analisar de forma precisa a estrutura dos quintais. Estas informações devem ser levadas em consideração por parte dos gestores do Parque Nacional de Sete Cidades, visto que a comunidade encontra-se no entorno desta unidade de conservação, a fim de fortalecer a sustentabilidade ambiental tanto dos quintais, quanto deste espaço de preservação e conservação.

\section{Conflito de interesses}

Os autores declaram não haver conflito de interesses.

\section{Referências}

Abdo, M. T. V. N; Valeri, S. V. Martins, A. L. M. Sistemas agroflorestais e agricultura familiar: uma parceria interessante. Revista Tecnologia \& Inovação Agropecuária, v. 1, n. 2, p. 49-59, 2009.

Abreu, M. C.; Silva, P. H.; Oliveira, Y. R. Vegetais cultivados em quintais rurais piauienses com indicação anticâncer: uma busca pelo conhecimento tradicional. Ciência e Natura, v. 39, n. 1, p. 22-32, 2017. https://doi.org/10.5902/2179460X24219

Albuquerque, U. P.; Sousa, T. A.; Soldati, G. T. 0 "retorno" das pesquisas etnobiológicas para as comunidades. In: Albuquerque, U. P.; Lucena, R. F. P.; Cunha, L. V. F. C. (Eds.). Métodos e técnicas na pesquisa etnobiológica e etnoecológica. Recife: NUPEEA, 2010.

Albuquerque, U.P.; Andrade, L. H.C. Conhecimento botânico tradicional e conservação em uma área de Caatinga no Estado de Pernambuco, Nordeste do Brasil. Acta Botanica Brasilica, v. 16, n. 3, p. 273285, 2002a. https://doi.org/10.1590/S010233062002000300004

Albuquerque, U. P.; Andrade, L. H. C. Uso de recursos da Caatinga: o caso do Agreste de Pernambuco, (Nordeste do Brasil). Interciencia, v. 27, n. 7, p. 336-346, 2002b.

Albuquerque, U. P.; Cavalcanti, L. H.; Caballero, J. Structure and floristics of homegardens in Northeastern Brazil. Journal of Arid Enviroments, v. 62, n. 3, p. 491-506, 2005a. https://doi.org/10.1016/j.jaridenv. 2005.01.003

Albuquerque, U. P.; Silva, A. C. O.; Andrade, L. H. C. Use of plant resources in a seasonal dry forest (Northeastern Brazil). Acta Botanica Brasilica, v. 19 , n. 1, p. 27-38, 2005b. https://doi.org/10.1590/S0102-33062005 000100004

Almeida, L. S.; Gama, J. R. V. Quintais agroflorestais: estrutura, composição florística e aspectos socioambientais em área de assentamento rural na Amazônia Brasileira. Ciência Florestal, v. 24, n. 4, p. 1037-1048, 2014. https://doi.org/ 10.5902/1980509816617

Alves, R. R. N.; Policarpo, I. S.; Barboza, R. R. D.; Araujo, H. F. P. Perception and use of biodiversity in the vicinity of an urban conservation area, North Eastern Brazil. Indian Journal of Traditional Knowledge, v. 16, p. 44-50, 2017.

Araujo, Q. R.; Loureiro, G. A. H. A.; Santana, S. O.; Baligar, V. C. Soil classification and carbon storage in Cacao Agroforestry Farming Systems of Bahia, Brazil. Journal of Sustainable Forestry, v. 32, n. 6, p. 625-647, 2013. https://doi.org/10.1080/10549811. 2013.799037

Boni, V. Gênero: o doméstico e o produtivo na agroindústria familiar. Anais do VII Congresso Latino-Americano de Sociologia Rural, Equador, p. 38-39, 2006. 
Carniello, M. A.; Silva, R. S.; Cruz, M. A. B.; Guarim Neto, G. Quintais urbanos de Mirassol d'Oeste-MT, Brasil: uma abordagem etnobotânica. Acta Amazonica, v. 40, n. 3, p. 451-470, 2010. https://doi.org/10.1590/ S0044-59672010000300005

Carvalho, T. K. N.; Abreu, D. B. O.; Lucena, C. M.; Pedroza, K. M.; Vasconcelos Neto, C. F. A.; Alves, C. A. B.; Felix, L. P.; Florentino, A. T. N.; Alves, R. R. N.; Andrade, L. A.; Lucena, R. F. P. Structure and floristics of home gardens in an altitude marsh in Northeastern Brazil. Ethnobotany Research and Applications, v. 11 , p. 29-48, 2013.

Castanho Filho, E. P. Floresta e bioenergia. Informações Econômicas, v. 38, n. 2, p. 5267, 2008.

Cavalcante, L. C. D. Parque Nacional de Sete Cidades, Piauí, Brasil: biodiversidade, arqueologia e conservação de arte rupestre. MNEME - Revista de Humanidades, v. 14, n. 32, p. 1-22, 2013.

CEPRO - Centro de Pesquisas Econômicas e Sociais do Estado do Piauí. Cerrados piauienses: Estudo preliminar de suas potencialidades. Teresina: Secretaria de Planejamento, 1992.

Chaves, A. R. S.; Castro, R. R. A.; Menezes, A. A busca pela ascensão feminina no PDS Virola Jatobá, Anapu-PA. Revista Estudos Feministas, v. 26, n. 1, p. 1-15, 2018.

Chitsondzo, C. C. E.; Silva, I. C. Quintais caseiros em Machipanda, Distrito de Manica, Moçambique. Pesquisa Florestal Brasileira, v. 33, n. 74, p. 127-135, 2013. https://doi.org/10.4336/2013.pfb.33.74.413

Cordeiro, R. L. M. Agricultura familiar, trabalho feminino e ação coletiva. Anais do IV Encontro Nacional da Associação Brasileira de Psicologia Social, Rio de Janeiro, ABRAPSO, p. 1-13, 2007.

Cunha, L. V.F.C.; Albuquerque, U.P. Quantitative ethnobotany in an atlantic forest fragment of Northeastern Brazil: Implications to conservation. Environemental Monitoring and Assessment, v. 114, n. 1/2, p. 1-25, 2006. https://doi.org/10.1007/ s10661-006-1074-9

Damaceno, J. B. D.; Lobato, A. C. N. Caracterização de um quintal agroflorestal na Amazônia Central, Brasil. Revista Brasileira de Gestão Ambiental e Sustententabili dade, v. 6, n. 12, p. 163-173, 2019. https://doi.org/10.21438/rbgas.061214

Ducke, A.; Black, G. A. Phytogeographical notes on the Brazilian Amazon. Anais da Academia Brasileira de Ciências, v. 25, n. 1, p. 1-46, 1953.

Emperaire, L. Végétation de l'état du Piauí (Brésil). Societé de Biogéographie, n. 60, p. 151-163, 1985.

Fernandes, C. A. F.; Matsumoto, S. N.; Fernandes, V.S. Carbon stock in the development of different designs of biodiverse agroforestry systems. Revista Brasileira de Engenharia Agrícola e Ambiental, v. 22, n. 10, p. 720-725, 2018. https://doi.org/10.1590/1807-1929/ agriambi.v22n10p720-725

Figueiredo Junior, O.; Hamada, M. O. S.; Souza, O. P. S.; Correa, R. F. Levantamento florístico dos quintais agroflorestais do PDS Virola Jatobá em Anapu, Pará. Enciclopédia Biosfera, v. 9, n. 17, p. 1793-1805, 2013.

Florentino, A. T. N.; Araújo, E. L.; Albuquerque, U. P. Contribuição de quintais agroflorestais na conservação de plantas da Caatinga, Município de Caruaru, PE, Brasil. Acta Botânica Brasilica, v. 21, n. 1, p. 37-47, 2007. https://doi.org/10.1590/S0102-33062 007000100005

Foguesatto, C. R.; Artuzo, F. D.; Lago, A.; Machado, J. A. D. Fatores relevantes para a tomada de decisão dos jovens no processo de sucessão geracional na agricultura familiar. Revista Paranaense de Desenvolvimento, v. 37, n. 130, p. 15-28, 2016.

Forzza, R. C.; Leitman, P. M.; Costa, A.; Carvalho, J. R. A. A.; Peixoto, A. L.; Walter, B. M. T.; Bicudo, C.; Zappi, D.; Costa, D. P.; Lleras, E.; Martinelli, G.; Lima, H. C.; Prado, J.; Stehmann, J. R.; Baumgratz, J. F. A.; Pirani, J. R.; Sylvestre, L. S.; Maia, L. C.; Lohmann, L. G.; Paganucci, L.; Silveira, M.; Nadruz, M.; Mamede, M. C. H.; Bastos, M. N. C.; Morim, M. P.; Barbosa, M. R.; Menezes, M.; Hopkins, M.; Secco, R.; Cavalcanti, T.; Souza, V. C. Catálogo de plantas e fungos do Brasil. Rio de Janeiro: Instituto de Pesquisas Jardim Botânico do Rio de Janeiro, 2010. v. 2.

Franco, E. A. P.; Barros, R. F. M. Uso e diversidade de plantas medicinais no Quilombo Olho d'Água dos Pires, Esperantina, Piauí. Revista Brasileira de Plantas Medicinais, v. 8, n. 3, p. 78-88, 2006. 
Galizoni, F. M.; Ribeiro, E. M. Trabalho feminino na agricultura familiar do Alto Jequitinhonha, Minas Gerais. Anais do XL Congresso Brasileiro de Economia e Sociologia Rural, Cuiabá, Brasília, SOBER, 2004.

Gbedomon, R. C.; Salako, V. K.; Fandohan, A. B.; Idohou, A. F. R.; Kakaї, R. G.; Assogbadjo, A. E. Functional diversity of home gardens and their agrobiodiversity conservation benefits in Benin, West Africa. Journal of Ethnobiology and Ethnomedicine, 13:66, 2017. https://doi.org/10.1186/s13002-0170192-5

Geohack. GeoHack - Brasileira (Piauí). Disponível em: <https://tools.wmflabs.org/ geohack/geohack.php?language=pt\&pagena me=Brasileira_(Piauí) \&params=04_07_51_S_ 41_46_55_W_type:city_region:BR_scale:7500 0>. Acesso em: 20 abr. 2019.

Guarim Neto, G.; Amaral, C. N. Aspectos etnobotânicos de quintais tradicionais dos moradores de Rosário Oeste, Mato Grosso, Brasil. Polibotânica, n. 29, p. 191-212, 2010.

Hoogesteger van Dijk, V. M.; Casas, A.; Moreno-Calles, A.I. Semiarid ethnoagroforestry management: Tajos in the Sierra Gorda, Guanajuato, Mexico. Journal of Ethnobiology and Ethnomedicine, 13:34, 2017. https://doi.org/10.1186/s13002-0170162-y

Huntington, H. P. Using traditional ecological knowledge in science: Methods and applications. Ecological Applications, v. 10, n. 5, p. $1270-1274,2000$. https://doi.org/ 10.1890/1051-0761(2000)010[1270: UTEKIS]2.0.CO;2

IBGE - Instituto Brasileiro de Geografia e Estatística. Censo 2010. Disponível em: <https://cidades.ibge.gov.br/brasil/pi/brasil eira/panorama>. Acesso em: 10 abr. 2019.

Kumar, B. M.; Nair, P. K. R. The enigma of tropical homegardens. Agroforestry Systems, v. 61, n. 1/3, p. 135-152, 2004. https://doi.org/10.1023/B:AGF0.000002899 5.13227.ca

Lima, G. D. S.; Lima, J. R. F.; Silva, N.; Oliveira, R. S.; Lucena, R. F. P. Inventory in situ of plant resources used as fuel in the Semiarid Region of Northeast Brazil. Brazilian Journal of Biological Sciences, v. 3, n 5, p. 45-62, 2016. https://doi.org/10.21472/bjbs.030505
Lins-Neto, E. M. F.; Peroni, N.; Maranhão, C. M. C.; Maciel, M. I. S.; Albuquerque, U. P. Analysis of umbu (Spondias tuberosa Arruda (Anacardiaceae)) in different landscape management regimes. A process of incipient domestication? Environmental Monitoring and Assessment, v. 184, n. 7, p. 4489-4499, 2012. https://doi.org/10.1007/s10661-0112280-7

Lucena, C. M.; Carvalho, T. K. N.; Ribeiro, J. E. S.; Quirino, Z. G. M.; Casas, A.; Lucena, R. F. P. Conhecimento botânico tradicional sobre cactáceas no Semiárido do Brasil. Gaia Scientia, v. 9, n. 2, p. 77-99, 2015.

Lucena, R. F. P.; Albuquerque, U. P.; Monteiro, J. M.; Almeida, C. F. C. B. R.; Florentino, A. T. N.; Ferraz, J. S. F. Useful plants of the semiArid Northeastern Region of Brazil: A look at their consevation and sustainable use. Environmental Monitoring and Assessment, v. 125, n. 1/3, p. 281-290, 2007. https://doi.org/10.1007/s10661-006-9521-1

Lucena, R. F. P.; Carvalho, T. K. N.; Ferreira, E. C.; Bonifácio, K. M.; Santos, S. S.; Meira, K. R. F.; Lucena, C. M. Plantas e animais medicinais: uma abordagem etnobiológica e etnoecológica. In: Lucena, R. F. P.; Lucena, C. M.; Carvalho, T. K. N.; Ferreira, E. C.; Bonifácio, K. M. (Org.). Plantas e animais medicinais da Paraíba: um olhar da Etnobiologia e Etnoecologia. Cabedelo: IESP, 2018. p. 8-19.

Lucena, R. F. P.; Pedrosa, K. M.; Carvalho, T. K. N.; Guerra, N. M.; Ribeiro, J. E. S.; Ferreira, E. C. Conhecimento local e uso de espécies vegetais nativas da região da Serra de Santa Catarina, Paraíba, Nordeste do Brasil. FLOVET - Boletim do Grupo de Pesquisa da Flora, Vegetação e Etnobotânica, v. 1, n. 9, p. 158-179, 2017.

Lucena, R. F. P.; Soares, T. C.; VasconcelosNeto, C. F. A.; Carvalho, T. K. N.; Lucena, C. M.; Alves, R. R. N. Uso de recursos vegetais da Caatinga em uma comunidade rural no Curimataú paraibano (Nordeste do Brasil). Polibotánica, n. 34, p. 217-238, 2012.

Novais, A. M.; Guarim Neto, G.; Guarim, V. L. M. S.; Pasa, M. C. Os quintais e a flora local: um estudo na Comunidade Jardim Paraíso, Cáceres-MT, Brasil. Revista Biodiversidade, v. 10, n. 1, p. 3-11, 2011.

Nunes, E. M.; Guerra, N. M.; Arévalo-Marín, E.; Alves, C. A. B.; Nascimento, V. T.; Cruz, D. D.; Ladio, A. H.; Silva, S. M.; Oliveira, R. S.; Lucena, 
R. F. P. Local botanical knowledge of native food plants in the Semiarid Region of Brazil. Journal of Ethnobiology and Ethnomedicine, 14:49, 2018, https://doi.org/10.1186/s13002-018-0249-0

Nunes, G. M. Disponibilidade e uso de plantas medicinais em um Parque Nacional do Nordeste do Brasil. João Pessoa: Universidade Federal da Paraíba, 2019. (Dissertação de mestrado).

Oliveira, M. E. A.; Castro, A. A. J. F.; Martins, F. R. Fisionomias vegetacionais do Parque Nacional de Sete Cidades, Piauí, NE do Brasil. In: Araújo, A. S. F. (Ed.). Biodiversidade de solo e plantas (Parque Nacional de Sete Cidades). Teresina: EDUFPI, 2017. p. 12-34.

Oakley, E. Quintais domésticos: uma responsabilidade cultural. Agriculturas, v. 1, n. 1, p. 37-39, 2004.

Pereira, L. G.; Vieira, F. J.; Alencar, N. L.; Carvalho, F. P. A.; Barros, R. F. M. Diversidade florística em quintais do Nordeste brasileiro: um estudo etnobotânico em comunidades rurais em Monsenhor Gil/PI. Revista Espacios, v. 37, n. 20, p. 11, 2016.

Pereira, S. C. B.; Jardim, I. N.; Freitas, A. D. D.; Paraense, V. C. Levantamento etnobotânico de quintais agroflorestais em agrovila no Município de Altamira, Pará. Revista Verde de Agroecologia e Desenvolvimento Sustentável, v. 13, n. 2, p. 200-208, 2018. https://doi.org/10.18378/rvads.v13i2.5292

Phillips, O.; Gentry, A. H. The useful plants of Tambopata, Peru: I Statistical hypothesis testing with a new quantitative technique. Economic Botany, v. 47, n. 1, p. 15-32, 1993a. https://doi.org/10.1007/BF02862203

Phillips, O.; Gentry, A. H. The useful plants of Tambopata, Peru: II Additional hypothesis testing in quantitative Ethnobotany. Economic Botany, v. 47, n. 1, p. 33-43, 1993b. https://doi.org/10.1007/BF02862204

Pinho, R. C.; Miller, R. P.; Alfaia, S. S. Agroforestry and the improvement of soil fertility: A view from Amazonia. Applied and Environmental Soil Science, v. 2012, Article ID 616383, 2012. https://doi.org/10.1155/ $2012 / 616383$

Prado, A. C. C.; Rangel, E. B.; Sousa, H. C.; Messias, M. C. T. B. Etnobotânica como subsídio à gestão socioambiental de uma unidade de conservação de uso sustentável. Rodriguésia, v. 70, e02032017, 2019. https://doi.org/10.1590/2175-78602019 70019

Quaresma, A. P.; Almeida, R. H. C.; Oliveira, C. M.; Kato, O. R. Composição florística e faunística de quintais agroflorestais da agricultura familiar no nordeste paraense. Revista Verde de Agroecologia e Desenvolvimento Sustentável, v. 10, n. 5, p. 76-84, 2015. https://doi.org/10.18378/ rvads.v10i5.3706

Ribeiro, J. E. S.; Carvalho, T. K. N.; Ribeiro, J. P. O.; Guerra, N. M.; Silva, N.; Pedrosa, K. M.; Alves, C. A. B.; Souza-Júnior, S. P.; Souto, J. S.; Nunes, A. T.; Lima, J. R. F.; Oliveira, R. S.; Lucena, R. F. P. Ecological apparency hypothesis and availability of useful plants: Testing different use values. Ethnobotany Research and Applications, v. 12, p. 415432, 2014a.

Ribeiro, J. F.; Walter, B. M. T. Fitofisionomias do Bioma Cerrado. In: Sano, S. M.; Almeida, S. P. (Eds.). Cerrado: ambiente e flora. Planaltina: EMBRAPA-CPAC, 1998.

Ribeiro, J. P. O.; Carvalho, T. K. N.; Ribeiro, J. E. S.; Sousa, R. F.; Lima, J. R. F.; Oliveira, R. S.; Alves, C. A. B.; Jardim, A. N. D.; Lucena, R. F. P. Can ecological apparency explain the use of plant species in the Semi-Arid Depression of Northeastern Brazil? Acta Botanica Brasilica, v. 28, n. 3, p. 476-483, 2014 b. https://doi.org/10.1590/0102-33062014 abb2758

Ribeiro, R. V.; Bieski, I. G. C.; Balogun, S. O.; Matins, D. T. O. Ethnobotanical study of medicinal plants used by ribeirinhos in the North Araguaia Microregion, Mato Grosso, Brazil. Journal of Ethnopharmacology, v. 205 , p. $69-102$, 2017. https://doi.org/ 10.1016/j.jep.2017.04.023

Ritter, M. R.; Silva, T. C.; Araújo, E. L.; Albuquerque, U. P. Bibliometric analysis of ethnobotanical research in Brazil (19882013). Acta Botanica Brasilica, v. 29, n. 1, p. 113-119, 2015. https://doi.org/10.1590/ 0102-33062014abb3524

Rossato, S. C.; Leitão-Filho, H. F.; Begossi, A. Ethnobotany of caiçaras of the Atlantic Forest Coast (Brazil). Economic Botany, v. 53, n. 4, p. 387-395, 1999. https://doi.org/10.1007/ BF02866716 
Roque, A. A.; Rocha, R. M.; Loiola, M. I. B. Uso e diversidade de plantas medicinais da Caatinga na Comunidade Rural de Laginhas, Município de Caicó, Rio Grande do Norte (Nordeste do Brasil). Revista Brasileira de Plantas Medicinais, v. 12 , n. 1, p. 31-42, 2010. https://doi.org/10.1590/S151605722010000100006

Shen, S.; Xu, G.; Li, D.; Clements, D. R.; Zhang, F.; Jin, G.; Wu, J.;Wei, P.; Lin, S.; Xue, D. Agrobiodiversity and in situ conservation in ethnic minority communities of Xishuangbanna in Yunnan Province, Southwest China. Journal of Ethnobiology and Ethnomedicine, v. 13, n. 28, 2017, https://doi.org/10.1186/s13002-017-0158-7

Silva, A. A. S.; Ferreira, E. C.; Santos, S. S.; Carvalho, T. K. N.; Lucena, C. M.; Nunes, G. M.; Madruga Filho, V. J. P.; Lucena, R. F. P.; Lucena, R. F. P. Utilização de plantas na veterinária popular no Semiárido da Paraíba, Nordeste do Brasil. FLOVET - Boletim do grupo de pesquisa da Flora, Vegetação e Etnobotânica, n. 1, p. 37-60, 2018.

Silva, A. J. R.; Andrade, L. H. C. Etnobotânica nordestina: estudo comparativo da relação entre comunidades e vegetação na Zona do Litoral - Mata do Estado de Pernambuco, Brasil. Acta Botanica Brasilica, v. 19, n. 1, p. 45-60, 2005. https://doi.org/10.1590/ S0102-3306200500010000

Silva, P. H.; Oliveira, Y. R.; Abreu, M. C. Uma abordagem etnobotânica acerca das plantas úteis cultivadas em quintais em uma comunidade rural do semiárido piauiense, Nordeste do Brasil. Journal of Environmental Analysis and Progress, v. 2, n. 2, p. 144-159, 2017. https://doi.org/ 10.24221/jeap.2.2.2017.1175.144-159

Sousa, R. F.; Silva, R. A. R.; Rocha, T. G. F.; Santana, J. A. S.; Vieira F. A. Etnoecologia e Etnobotânica da palmeira carnaúba no semiárido brasileiro. Cerne, v. 21, n. 4, p. 587-594, 2015. https://doi.org/10.1590/ 01047760201521041764

Spiller, C.; Coelho, M. F. B.; Gonçalves, V. D.; Pinto, L. P.; Camili, E. C. Estudo etnobotânico em quintais agroflorestais em bairro na Cidade de Cuiabá, Mato Grosso. Revista Verde de Agroecologia e Desenvolvimento Sustentável, v. 11, n. 5, p. 138-142, 2016. https://doi.org/10.18378/rvads.v11i5.3832

Vieira, T. A.; Rosa, L. S.; Santos, M. M. L. S. Agrobiodiversidade de quintais agroflorestais no Município de Bonito, Estado do Pará. Revista de Ciências Agrárias, v. 55, n. 3, p. 159-166, 2012.

Informação da Licença: Este é um artigo Open Access distribuído sob os termos da Licença Creative Commons Attribution, que permite uso irrestrito, distribuição e reprodução em qualquer meio, desde que a obra original seja devidamente citada. 